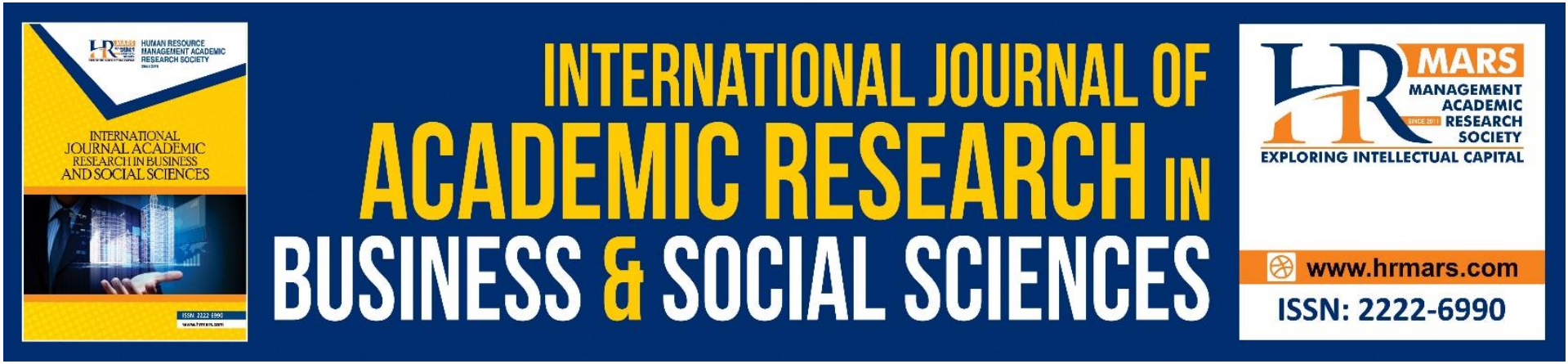

\title{
A Pilot Study of Covid-19 Vaccination Readiness
}

Fahirah Syaliza Mokhtar, Zamri Chik, Ahmad Munir Mohd Salleh, Muhammad Abi Sofian Abdul Halim, Rusnifaezah Musa, Noor Muthmainnah Hamdul Hadi

To Link this Article: http://dx.doi.org/10.6007/IJARBSS/v12-i1/11642

DOI:10.6007/IJARBSS/v12-i1/11642

Received: 12 November 2021, Revised: 16 December 2021, Accepted: 06 January 2022

Published Online: 27 January 2022

In-Text Citation: (Mokhtar et al., 2022)

To Cite this Article: Mokhtar, F. S., Chik, Z., Salleh, A. M. M., Halim, M. A. S. A., Musa, R., \& Hadi, N. M. H. (2022). A Pilot Study of Covid-19 Vaccination Readiness. International Journal of Academic Research in Business and Social Sciences, 12(1), 2150-2166.

Copyright: (c) 2022 The Author(s)

Published by Human Resource Management Academic Research Society (www.hrmars.com)

This article is published under the Creative Commons Attribution (CC BY 4.0) license. Anyone may reproduce, distribute, translate and create derivative works of this article (for both commercial and non0-commercial purposes), subject to full attribution to the original publication and authors. The full terms of this license may be seen at: http://creativecommons.org/licences/by/4.0/legalcode

Vol. 12, No. 1, 2022, Pg. 2150- 2166

Full Terms \& Conditions of access and use can be found at http://hrmars.com/index.php/pages/detail/publication-ethics 


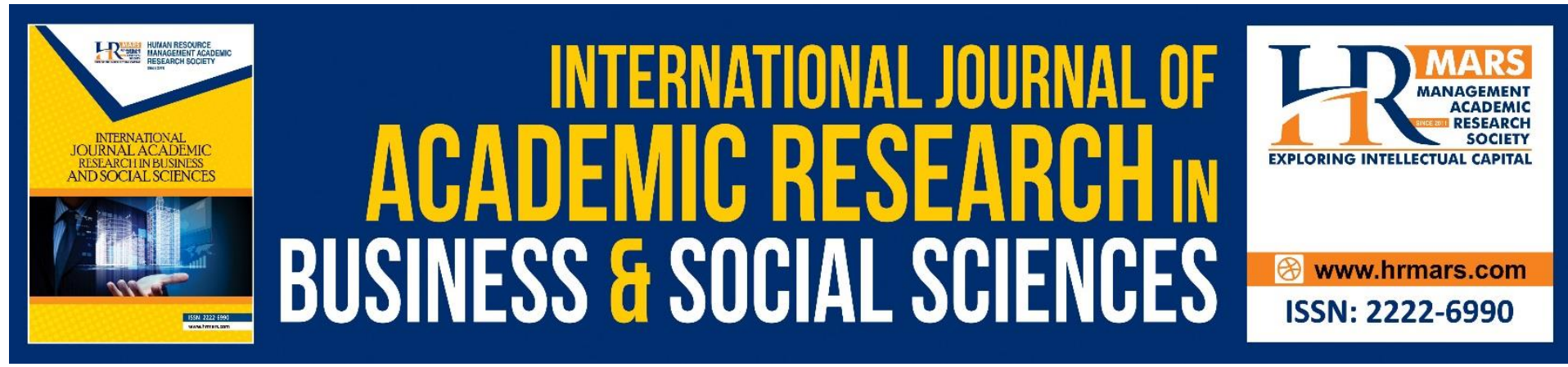

\title{
A Pilot Study of Covid-19 Vaccination Readiness
}

\section{Fahirah Syaliza Mokhtar ${ }^{1}$, Zamri Chik ${ }^{2}$, Ahmad Munir Mohd Salleh ${ }^{1}$, Muhammad Abi Sofian Abdul Halim¹, Rusnifaezah Musa $^{3}$, Noor Muthmainnah Hamdul Hadi ${ }^{4}$}

${ }^{1}$ Universiti Malaysia Terengganu Kuala Nerus 21030,Terengganu, ${ }^{2}$ Terengganu Strategic \& Integrity Institute, 20300 Kuala Terengganu, Terengganu, ${ }^{3}$ Aimst University, Semeling, 08100 Bedong, Kedah, ${ }^{4}$ Universiti Sultan Zainal Abidin, Kuala Nerus 21030, Terengganu

Corresponding Author Email: fahirah.mokhtar@umt.edu.my

\begin{abstract}
The COVID-19 vaccination program in Malaysia is an effort launched by the Malaysian government as a means of containing the spread of coronavirus disease 2019 (COVID-19) and ending the outbreak in Malaysia by developing herd immunity among its citizens and noncitizen. A major effort will be required from health agencies, non-governmental organizations, industries, national and also state governments. In some states, low vaccination rates have resulted in outbreaks of Covid-19, while also impeding the government's efforts to achieve its aim. The goal of this study is to establish the antecedents of Covid-19 vaccination acceptability in which to establish the data's reliability and validity, a two-stage pilot study was conducted. Several antecedents were identified and examined and analysed using SPSS software. Findings of study in first stage postulated the items were validated and the elimination of more than $20 \%$ items indicated that item validity had been violated. Meanwhile, the second pilot tests produced high internal consistency of above 0.7 of the minimal value for cronbach alpha after further improvement. In summary, this paper validated the measurement of research variables and not all items can be used in examining the vaccine readiness in Malaysia context of study. The actual data will use the item validation based on this pilot study.
\end{abstract}

Keywords: COVID-19 Vaccine Readiness, Knowledge, Due Diligence, Religiosity, Factor Analysis.

\section{Introduction}

In March 2020, WHO announced Covid-19 was a pandemic in which the world took unprecedented lockdown measures affecting nearly a billion people subsequently putting everyone's lives to a grinding halt. No one could have expected the unprecedented lockdown measures triggered public health crisis and economic upheaval, devastating the lives of people and crumbling businesses to the ground. The presence of Covid-19 led scientists around the world scrambling to study about the deadly virus that has to date claimed almost 2.05 million lives and 96.2 million positive cases worldwide ${ }^{1}$ whereas in Malaysia, the disease

${ }^{1}$ WHO, 2020 https://covid19.who.int/ 
increased drastically from 642 lives in January to 3768 lives in June and a spike from 172,549 to 646,000 positive cases and is expected to increase until 2022 if not curbed ${ }^{2}$. As a result, it has become a global race to produce Covid-19 vaccine with the hope to eradicate if not to decrease the spreading of this disease.

The Ministry of Science, Technology and Innovation in collaboration with the Ministry of Health are the ministries responsible for the purchase and supply a of covid-19 vaccines to Malaysians. The Government has successfully secured Covid-19 vaccines from Pfizer Inc with BioNTech SE and Moderna Inc, which the clinical trials showing that it is effective up to $95 \%{ }^{3}$ The Government is also considering AstraZeneca Plc vaccine which has reported to be $90 \%$ effective ${ }^{4}$. In order to cater nearly $70 \%$ of Malaysian population, further negotiations took place of other Covid-19 vaccine manufacturing companies by the Special Committee on Guaranteed Access to Supply of Covid-19 Vaccines, namely Sinovac and CanSinoBIO from China and The Gamaleya National Center from Russia ${ }^{5}$ and then there are other Covid-19 vaccines on the market such as GlaxoSmithKline, Janssen (Johnson \& Johnson), Merck, Novavax, Sanofi, Takeda, Abbott and CureVac ${ }^{6}$. As with other vaccines before, it is predicted that Covid-19 vaccine is able to suppress this epidemic after the Malaysian population has reached 'herd immunity'.

This paper captures the current standing of Covid-19 vaccine readiness in Malaysia. In terms of contribution, this research paper shares findings and insights on the assessment of individual knowledge about covid-19 vaccine, their attitude towards vaccine, social and family support, government due diligence and religiousity. In terms of theoretical contribution, this paper empirically establish the compounding model of knowledge, attitude and practice model (Harapan, et al., 2019; Sherman, et al.,2021; Zhang, et al., 2021; Leidy \& Cerda, 2020) and health believe model theory (Wen, et al., 2020; Alqudeimat, etal., 2020; Lin, et al., 2020; Wong, et al., 2020; Chen, et al., 2021). While the religiosity construct may draw attention to examine people's behavior in vaccine readiness (Alqudeimat, et al., 2020; Sherman, et al., 2021). In Malaysia, almost 70 percent populations were muslims, thus this contributes to the literature of different view of vaccine readiness as muslims were particular in halal status of the vaccine. This research was based on Malaysian who reside in Terengganu, which offers a unique findings in terms of their acceptance where Terengganu is considered as one of rural state and the complacent attitude could pose a challenge in ramping up the herd immunity for the state.

\footnotetext{
${ }^{2}$ WHO, 2020 https://covid19.who.int/

3 Pfizer (2020), Pfizer and BioNTech Conclude Phase 3 Study of COVID-19 Vaccine Candidate, Meeting All Primary Efficacy Endpoints, https://www.pfizer.com/news/pressrelease/press-release-detail/pfizer-and-biontech-conclude-phase-3-study-covid-19-vaccine ${ }^{4}$ Jenny S (2020) AstraZeneca-Oxford Covid-19 Vaccine Up to 90\% Effective in Late-Stage Trials, Wall Street Journal, https://www.wsj.com/articles/astrazeneca-oxford-covid-19vaccine-up-to-90-effective-in-late-stage-trials-11606116047

${ }^{5}$ The Athira Yusof (2020), Khairy: RM2.05 billion for the purchase of Covid-19 vaccines for Malaysians, https://www.nst.com.my/news/government-publicpolicy/2020/12/651769/khairy-rm205-billion-purchase-covid-19-vaccines

${ }^{6}$ Donato Paolo Mancini (2020), Covid-19 vaccine makers lobby EU for legal protection, Financial Times, https://www.ft.com/content/12f7da5b-92c8-4050-bcea-e726b75eef4d
} 


\section{Literature Review}

The COVID-19 pandemic is expected to threaten the well-being of communities and economies around the world. Whenever a safe and effective COVID-19 vaccine becomes available, governments must be prepared to enable widespread, fair access and distribution (Lazarus, et al., 2021). This will necessitate enough health-care system capacity, as well as initiatives to improve vaccine trust and acceptability among those who administer it. The preparedness of Malaysians to receive the vaccine should be given attention to ensure the immunity status of the group among the community. A study done by Sheldenkar, et al. (2019) highlighted where the acceptance and uptake rate of influenza vaccinations across Asia, including Malaysia is low.

\section{Readiness}

Geiger, et al (2021) debated in their study vaccination readiness varies substantially among individuals even though vaccines has proven can fight to control the virus outbreak. Vaccination readiness is defined as a set of components that increase or decrease the individual's likelihood of getting vaccinated (Geiger, et al., 2021). In other studies, vaccine readiness were measure through community acceptance (Harapan, et al., 2020; Alqudeimat, et al., 2021) and intention to vaccine (Lackner \& Wang, 2021; Kwok, et al., 2021; Wang, et al., 2020). In recent study, researcher found out one major obstacle facing the achievement of getting community to vaccinated is vaccine hesitancy and skepticism among the population worldwide (El- Elimat, et al., 2021). The WHO Strategic Advisory Group of Experts defined vaccine reluctance as "delay in acceptance or refusal of vaccination despite availability of vaccination services" (MacDonald, 2015). Al-Mohaithef and Padhi(2020) described vaccine acceptability is determined by three factors: confidence, convenience, and complacency. In other studies, perceived severity, threat to health, perceived susceptibility of getting infected, side effect, lack of information, doubted effectiveness, accessibility, religious/personal beliefs, attitudes and support are among the factors contribute to acceptance and hesitancy of vaccines (Harapan, et al., 2020; Alqudeimat, et al., 2021; Lackner \& Wang, 2021; Kwok, et al., 2021; Wang, et al., 2020; El- Elimat, et al., 2021).

\section{Knowledge}

Knowledge is defined as a highly valued state in which a person is in cognitive contact with reality (Zagzebski, 2017). Meanwhile, Lehrer (2018) discuss in his book, Theory of knowledge emphasized that knowledge should be concern with the correct information where the application of knowledge to conclude a reasoning, confirm the hypotheses and refute others. In field of medical research, knowledge is looked as an awareness of community about one's information which regards as information of diseases, treatment, medicine, medical procedures and vaccines (Kassahun \& Mekonen, 2017; Napolitano, Napolitano \& Angelillo, 2017; Ricco, et al., 2017).

\section{Attitude}

Rheu (2020) defined an attitude as a person general evaluation toward an attitude object, which is generated from the past experience of learning that influences their thinking and acting about the object. Attitudes have been widely discussed and debated by previous scholars especially the attitude of subject group of exposing media content and relationship of individual's attitude towards different social group, economy, potical and health behavior (Rheu, 2020). In health study, attitude is defined as the way community thinks and behave 
towards the sickness, treatment, medicine and vaccines (Kassahun \& Mekonen, 2017; Rosso, et al., 2019; Ricco, et al., 2017) and were measure by looking at their positive and negative attitudes (Vergara et al., 2021; Hagemeister, et al., 2018; Gailbraith-Gyan, et al., 2019).

\section{Social Support}

In a health study, social support is defined as the perceived or actual receipt of social resources (e.g., tangible, emotional) and is one of the most reliable predictors of disease morbidity and mortality (Uchino, et al., 2018). In one study on the HPV vaccine acceptance, the social support is one of the important contributing factor in evaluating the degree of vaccine acceptance where the study also observe the mother-daughter relationship (Gailbraith-Gyan, et al., 2019). On the other side of story, some individuals may seek support from the people who already the experiences the sickness or vaccine uptakes. By looking at social media platform like google, facebook, twitter, some group may lead to vaccine hesitancy where a continuum of positive and negative stances toward vaccination exists on the internet (Elkin et al., 2020).

\section{Due Diligence}

Due diligence is commonly understood in the business world to refer to a process of investigation carried out by a company to identify and manage commercial risks. The main goal of due diligence is to confirm facts, data, and representations involved in a commercial transaction in order to determine the transaction's value, price, and risk, including the risk of future litigation (Bonnitcha \& McCorquodale, 2017). They go on to say that legal risks are frequently included in due diligence processes, and that the risk of legal liability is merely another business concern to be identified and managed in the context of a specific transaction. Due diligence is a word used to describe a collection of practises used by a company to identify and manage risks. It is not limited to mergers and acquisitions. Nanni, et al (2017) point out that during the vaccine procurement process, a government must conduct due diligence on vaccine supply, production capability, and high vaccine prices and delivery costs.

\section{Religion (Religiosity)}

Religiosity is defined differently by many researchers. Previous scholar defined religion as instrinsic behavior which refers to belief and identity (Allport \& Ross, 1967). Meanwhile, Koenig \& Bussing (2010) defines religious values as an expression that can be demonstrated by attendance to religious services; attitudes toward religious behaviors and involvement in religious activities. Another study discussed on specific combinations of religious affiliation and fundamentalism when investigating science attitudes and knowledge, which lends to a rather limited interpretation of the relation between religion and science (McPhetres \& Zuckerman, 2018).

\section{Research Method}

A pilot study is critical because it improves the instrument's precision (Zikmund 2003). It entails the collection of data from a smaller sample size than that used for primary data collection (Zikmund 1984). According to Abbott and Bordens (2011), a pilot study enables the evaluation of the performance of a research instrument. Pilot studies are advantageous in a variety of ways like it identifies flaws and errors in instruments (Cooper and Schindler 2011). This contributes to the better reliability and validity of the instrument (Ghauri and Grnhaug, 
2010). Pilot studies also facilitate in resolving questionnaire wording issues (Lee and Lings, 2010), comprehension and clarity issues (Saunders and Tosey, 2012), adequacy of instructions or directions issues (Bryman, 2008), questionnaire layout and attractiveness issues, and questionnaire timing and length issues (Saunders and Tosey, 2012). In summary, pilot testing benefits the instrument by increasing its quality (Bryman, 2008) and reliability and validity (Ghauri and Grnhaug, 2010). As a result, pilot study is important to be conducted as it helped to prove the reliability and appropriate of the data collection, so as to proceed with the future research instruments effectively (Rosli \& Sidek, 2013).

This pilot study employs a quantitative approach of research. The quantitative approach is appropriate for a deductive research, objective and outcome-oriented studies by using standards of validity and reliability of statistical procedures (Creswell, 2010). The nature of this study is a cross-sectional research whereby the data is collected, analyzed, and summarized statistically and conclusions are drawn at a single point in time. This study also used survey method in collecting the data as it is the best way to obtain information about belief, attitude, perception or opinion from people in their natural environment (Graziano \& Raulin, 2004; Babbie, 2004) and involves collection of sizable responses using the most economical approaches (Musa, 2017).

The pilot study in this paper used a 10-point Likert scale. A Likert scale is an interval scale commonly used in survey research employing questionnaire for data collection (Voleti 2019). A 10 point Likert scale will offer more variance than a smaller Likert scale, provide a higher degree of measurement precision and provide a better opportunity to detect changes and more power to explain a point of view (Wittink \& Bayer, 2003). The 10 scales used are: 1-Very Strongly Disagree, 2-Strongly Disagree, 3-Disagree, 4-Mostly Disagree, 5-Slightly Disagree, Slightly Agree, Mostly Agree, Agree, Strongly Agree and Very Strongly Agree. Moreover, questionnaires was designed in Bahasa to reach different level of respondent education and knowledge.

Factor analysis generally was performed with large sample sizes (Winter, et al., 2009). Guilford (1954) recommended a minimum sample size of 200 for consistent factor recovery. Meanwhile, in other study, a sample between 25 and 100 individuals is enough for pilot test (Cooper \& Schindler, 2011). Therefore, 100 questionnaires were distributed to citizen of Terengganu through online survey for validity and reliability purposes. As the rise of positive cases of infected covid-19, this constraint lead to researcher choose online survey method.

Employees from different state government agencies and commercial companies in Terengganu who are 18 years old and have not had the Covid-19 immunization took part in the pilot trial in March 2021. Within 5 days, 88 replies were received from the 100 surveys given. The data was evaluated with SPSS version 22 software to determine the item's validity and reliability. A few changes to the study items were made in response to the findings, and a second round of pilot testing was conducted to assess the item's dependability before the actual data was collected. In the second step of the pilot test, 30 questionnaires were distributed. 


\section{Results and Discussion \\ First Stage of Pilot Test}

The first part of the pilot test was conducted using an online survey utilizing Google Forms. A total of 100 surveys were distributed through WhatsApp groups confining to one particular university The screening questions include: '(1) Are you a Terengganu resident aged 18 and above? (2) Have you had your vaccinations?' were created in order to obtain the appropriate target group. Within 5 days, 88 replies were collected. There were no missing values or outliers in the data.

\section{Frequency Analysis}

Demographic analysis has been described in terms of twelves different areas; age, gender, residing location, educational level, occupation, religion, income, current diseases respondent has, history of Covid-19 infection, MySejahtera registration, search of information, and vaccine preference. The results of the descriptive analysis are shown in Table 1.1. In term of age, the majority of those who took part in the study were between the ages of 18 and 40 . More over half of the respondents or 67 percent were female and only had SPM qualification. 37.5 percent of respondents were B40, 51.1 percent were $\mathrm{M} 40$ and 11.4 percent were T20. High blood pressure and high cholesterol are two diseases that respondents have, and nearly all respondents are free of chronic diseases.

88 respondents are Terengganu citizens who have never been infected with the Covid-19 virus. However, 22.7 percent of respondents' families had infected with the virus. Almost a third of the respondents live with senior citizens. One of intriguing finding is that 97.7 percent of respondents agreed that they seek further information about the Covid-19 virus and vaccines. However, the highest percentage of information sources were those seeking information informally such as via whatsapp, telegram and social media applications such as facebook compared to the official $\mathrm{WHO}$ and $\mathrm{MOH}$ websites. The registration of Covid-19 vaccine through MySejahtera is still unsatisfactory where only 64.8 percent of the respondents are registered. Only two types of vaccines, Pfizer and Sinovac are preferred by respondents when it comes to vaccine choosing in which the majority chooses Pfizer because they believe in the credibility of the manufacturer. Another reason respondents chose these vaccines is that they believe these vaccines able to prevent and treat virus Covid-19.

Table 1.1

Respondent Profile for Pilot Test Stage 1

\begin{tabular}{llcc}
\hline & Frequency & Percentage \\
\hline A1. & Age: & & \\
& 18 years -25 years & 49 & 55.7 \\
26 years -40 years & 26 & 29.5 \\
41 years -64 years & 13 & 14.8 \\
65 years and above & 0 & 0 \\
Total & $\mathbf{8 8}$ & $\mathbf{1 0 0}$ \\
& Gender: & & \\
Male & & \\
& Female & 29 & 33.0 \\
& Total & 59 & 67.0 \\
\end{tabular}


A3. Residing Location:

Northern Zone

Central Zone

Southern Zone

Total

88

A4. Educational Level:

No formal education

0

Primary School

0

0

Secondary School

0

22.7

Diploma/ Matriculation

11.4

Bachelor Degree

10

47.7

Postgraduate (Master or PhD)

Total

A5. Occupation:

State government offices

Local authorities

State statutory bodies

22.7

Religious schools

Government-linked companies

Private companies

Federal Offices/ Federal Statutory Bodies

Self-employed

unemployed

38.6

Total

100

A6. Religion:

Muslim

88

100.0

Hindu

0

0

Budhha

0

0

Christian

0

0

Others

0

0

Total

88

100

A7. Income:

Less than RM4,850

RM4,850-RM10,959

$45 \quad 51.1$

More than RM10,959

10

Total

88

100

A8. Current illness:

Diabetes

1

1.1

High Blood

8.0

High Cholesterol (hypercholesterolemia) 


\begin{tabular}{lcc}
\hline chronic obstructive airway disease (asthma) & 0 & 0 \\
Chronic kidney disease & 0 & 0 \\
Heart failure & 0 & 0 \\
Cancer & 0 & 0 \\
No chronic diseases & 81 & 92.0 \\
Others: ................................. & 5 & 5.7
\end{tabular}

A9. Infected with COVID-19:

$\begin{array}{lcc}\text { Yes } & 0 & 0 \\ \text { No } & 88 & 100 \\ \text { Total } & 88 & 100\end{array}$

A10. Families infected with COVID-19:

$\begin{array}{lll}\text { Yes } & 20 & 22.7 \\ \text { No } & 68 & 77.3 \\ \text { Total } & 88 & 100\end{array}$

A11. Looking after the elderly:

Yes

No $\quad 62$

70.5

Total

$88 \quad 100$

A12. MySejahtera Registration:

Yes

No

Total

A13. Search for information

Yes

No

Total

A13a. Official information

Official website of the World Health Organization

(WHO)

Ministry of health Malaysia Official website

66.0

Instant messaging application (SMS)

Print media(Journal)

Official sites in social media (Facebook, Twitter,

$\begin{array}{cc}26 & 2.3 \\ 70 & 79.5\end{array}$
Instagram)

Others :.....

A13b. Unofficial information

Instant messaging applications (WhatsApp, Telegram, SMS)

Print media (magazines and newspapers) 


\begin{tabular}{llcc}
\hline Electronic media (TV, radio) & 57 & 64.8 \\
Blog & 3 & 3.4 \\
Others :................................... & & \\
A14. $\quad$ Types of vaccines & 84 & 95.5 \\
Pfizer & 1 & 1.1 \\
AstraZaneca UK & 0 & 0 \\
AstraZaneca Global & 3 & 3.4 \\
Sinovac & 0 & 0 \\
CanSinoBio & 0 & 0 \\
Sputnik V & 88 & 100 \\
Total & & \\
& & \\
A15. Reasons for choosing & & \\
It's safe. & 27 & 30.7 \\
It's expensive. & 14 & 15.9 \\
It is free & 17 & 19.3 \\
I trust manufacturers & 46 & 52.3 \\
Able to prevent and treat Covid-19 & 35 & 40.0 \\
Total & 88 & 100 \\
\hline
\end{tabular}

\section{Factor Analysis}

Factor analysis, a class of processes for reducing and summarising data in which each variable is presented as a linear combination of the underlying factors, is one of the most frequent approaches to measure construct validity (Malhotra \& Birks, 2020). It's also known as a multivariate methodology that confirms the operationally defined dimensions of a concept while also identifying which objects are most suited for each dimension (Sekaran \& Bougie, 2016). As a result, in this study, factor analysis was used to examine the interrelationships among a large number of variables and to explain these variables in terms of their common underlying dimensions (Hair et al., 2010).

This study consisted of 80 items where 15 items for readiness, 17 items for knowledge, 20 items for attitude were measured through six dimensions. Due diligence also is a multidimensional variable where 11 items measured in three dimensions. Support consisted of 10 items and religion consisted of 7 items. A varimax rotated principal components factor analysis was then conducted on all items for 6 variables separately. Here, only loadings of at least or more than 0.50 were included and as a result, factor was extracted for these variables based on the eigen value.

Overall, all 6 variables reach a minimum value of 0.6 for the Kaiser-Meyer-Olkin (KMO) measure of sample adequacy, and all variables score more than 0.7 for the $\mathrm{KMO}$, indicating that the items were associated and shared common characteristics. All tests of sphericity were found to be significant at p0.001, indicating that the correlations among the variables are suitable and thus provide a solid basis for factor analysis (Ho, 2006). Meanwhile, individual MSA values reached a minimum cut value of 0.5 , indicating that the data matrix was eligible for factor analysis. Meanwhile, factor loading for items ranged from 0.592 to 0.963 as showed in Table 1.2. 
The findings of factor analysis also indicated there are reduction of dimensions for variable attitude which is from 6 dimensions to 3 dimensions which are herd immunity, unforeseen future effect and pessimistic. Variable knowledge also formed 2 factors which are vaccine information and alternative treatment. Due diligence remain with 3 factors which are the financial assistance, credibility of the manufacturer, and ministry responsibility. Meanwhile social support, religion and readiness remain to have 1 factor respectively. Although the loadings achieve minimum value suggested by Nunally and Bernstein (1994), there were 28 items deleted due to the factor loadings.

Table 1.2 below demonstrate the factor loadings of each items and the value of cronbach alpha for each variable(s) and dimension(s). According to Hair et al. (2017), a researcher is allowed to drop items up to 20 percent of the total number of items in the measurement model without compromising content validity. The total number of items dropped in this study is 28 items representing thirty five percent (35\%) of the total number of items in the measurement model. Thus, the percentage of items that have been dropped does violate the specified conditions. All items dropped indeed have a load of factors below 0.60 as prescribed by Nunally and Bernstein (1994).

Hair et al. (2010) have provided guidelines for the values of coefficient alpha, also referred to as Cronbach's alpha which range from 0 to 1 . Table 3.8 shows the rule of thumb to interpret alpha values as suggested by George and Mallery (2002) and Hair et al. (2006) explained the interpretation of alpha values must be based on the rule of thumb where the values of alpha below than 0.6 consider poor and acceptable, 0.6 to 0.7 consider moderate, alpha value between 0.7 to 0.8 is good and above than 0.8 is excellent. However, as a pre-caution, Hair et al. $(2006,2010)$ added that if the value of coefficient alpha recorded more than 0.95 , the items should be inspected to ensure that they are measuring the different aspects of the concept. Based on the findings (Table 1.2), alternative treatment, dimension under knowledge and financial assistance, dimension under due diligence have poor inter consistency value. While for manufacturer dimension under due diligence recorded alpha value more than 0.95 which is at 0.966 . Hence, researchers agreed to revised the items in the first pilot test as the items have validity and reliability issue and conduct a second pilot test.

Table 1.2

Factor analysis of research variables

Variable(s), Dimension(s) and Items

Loadings

KNOWLEDGE

Vaccine information

Without massive vaccination programs, Covid-19 would still exist.

0.891

The efficacy of vaccines Covid-19 has been extensively proven.

0.885

I understand what I read about Covid-19 virus.

0.830

Vaccines Covid-19 are 100\% effective.

0.791

There is other strain of Covid-19 that can infect humans, including those that

0.756

cause the common cold.

\section{Cronbach alpha}

\section{Alternative treatment}

Antibiotics are an effective treatment for Covid-19.

Flu vaccine will protect me from Covid-19.

There is no evidence that eating garlic will protect me against the Covid-19. 


\section{Cronbach alpha}

\section{ATTITUDE}

\section{Mistrust of Benefit}

Although Covid-19 vaccines appear to be safe, there may be problems that we yet to discover.

I believe I can still be infected with Covid-19 after vaccination.

I am concerned about my financial implication if i suffer serious side effects of

Covid-19 vaccine.

I'm concerned about the unknown side effects of Covid-19 vaccines in the future.

Natural exposure to viruses and germs gives the safest protection from Covid-19.

Covid-19 vaccines can cause unforeseen problems and side effects particularly for high-risk patients.

\section{Cronbach alpha}

\section{Pessimistic}

I don't believe Covid-19 vaccines can stop the spreading of Covid-19.

I don't feel vaccination Covid-19 is safe for me.

Pharmaceutical companies only focused on profit gain from the production of the covid-19 vaccine, but do not care about the safety of vaccine recipients entirely. Authorities promote vaccination for financial gain, rather than for the welfare of the public.

\section{Cronbach alpha}

\section{Herd Immunity}

It is important to get vaccinated against Covid-19 in order to protect others.

It is important to achieve herd immunity in order to eradicate the pandemic Covid-19.

\section{Cronbach alpha}

\section{FAMILY/SOCIAL SUPPORT}

My family provides me with the emotional support and assistance I need. 19.

My family makes every effort to persuade me to get the COVID-19 vaccine.

There is a special person with whom I can share my decision to take part in the COVID-19 immunization program.

My friends really having been working hard to persuade me to get vaccinated of COVID-19.

I have friends with whom I can share my decision of participating COVID-19 immunization program.

My family is willing to help me in making choices.

I can talk about my health problems with my friends.

\section{DUE DILIGENCE}

\section{Manufacturer Credibility}

Before purchasing the COVID-19 vaccine, the ministry involved had made due diligence on risk studies and legal problems of the purchase of COVID-19 vaccine. 
The collaboration between governments and ministries has developed a comprehensive policy before purchasing the COVID-19 vaccine.

I am concerned about my financial implication if $\mathrm{i}$ suffer serious side effects of Covid-19 vaccine.

The Government initiated the immunization of the COVID-19 programme by providing assurance that it will provide financial assistance to those affected in the event of serious side effects.

The purchase of the COVID-19 vaccine was made after the National Pharmaceutical Regulatory Agency (NPRA) Malaysia Approved the Covid-19 Vaccine.

The government simply chose pharmaceuticals that had high transparency in vaccine attempts.

\section{Cronbach alpha}

\section{Ministry Responsibility}

The Ministry responsible for having extensive experience handles the COVID-19 vaccine immunization program.

The Ministry responsible for the purchase of the COVID-19 vaccine carries out its duties properly.

The Ministry of Science, Technology and Innovation and the Ministry of Health efficiently implemented the COVID-19 vaccine immunization program.

\section{Cronbach alpha}

\section{Financial Assistance}

The government provides free COVID-19 vaccine to the people.

The purchase of the COVID-19 vaccine is one of the government's efforts to revive the country's economy.

\section{Cronbach alpha}

\section{RELIGIOUSITY}

I am very concerned about the halalness of COVID 19 vaccine.

Halal principle is concerned with hygiene and safety of vaccine Covid-19. $\quad 0.901$

I must know how COVID- 19 vaccine being produced.

\section{Cronbach alpha}

\section{READINESS}

I want to be vaccinated.

I advise friends and family to get vaccinated for Covid-19.

I understand about the importance of COVID-19 vaccines for my life.

I have no objection if my employer impose a policy for all employees to be vaccinated for Covid-19.

I received good source of information about COVID-19 vaccine from KKM.

I do not want COVID-19 vaccine because this virus is not easily treated. 


\section{Second Stage of Pilot Test}

The second pilot study was conducted with 30 different respondents from the first pilot research after modifications were made based on the findings of the first pilot research. The researchers revised 11 items out of 80 in the first phase pilot test since they were irrelevant and did not fit with the study's aims. According to the findings of the analysis, the item's reliability rate in the second phase pilot trial was higher than in the first. Table 1.3 shows the results of the second phase's reliability analysis.

In the second phase pilot study, only the reliability analysis of the items was conducted due to data collection constraints $(n=30)$, whereby factor analysis required at least 80 respondents (Hair, et al., 2010). Sekaran and Bougie (2010) pointed out that pilot studies which are commonly being conducted on a small scale, by interviewing individuals or gathering information from a limited number of occurrences, are not uncommon in exploratory research. In this regard, as recommended by Robbins (1999) that sample size for pilot test should range from 25 to 75 , a total of 30 questionnaires were collected through selfadministered to the population in order to conduct the pilot test. Based on the analysis of construct reliability analysis (Table 1.3 ) proves the cronbach alpha value for all constructs increased after improving the order and structure of sentences on the questionnaire item.

\begin{tabular}{lcccc}
\hline \multirow{2}{*}{ VARIABLE } & NO. OF & CRONBACH & \multicolumn{2}{c}{ SCALE IF ITEM DELETED } \\
\cline { 4 - 5 } & ITEM & ALPHA & NOF & CRONBACH \\
ITEM & ALPHA \\
\hline 1. KNOWLEDGE & 13 & 0.657 & 12 & 0.735 \\
2. ATTITUDE & 19 & 0.819 & & \\
Mistrust Vaccine Benefit & 3 & 0.613 & 2 & 0.886 \\
Future Effect & 3 & 0.868 & & \\
Commercial Profiteering & 3 & 0.864 & & \\
Natural Immunity & 3 & 0.814 & & \\
Herd Immunity & 4 & 0.833 & & \\
Vaccine Origin & 3 & 0.487 & 2 & \\
3. FAMILY/SOCIAL SUPPORT & 9 & 0.919 & & \\
4. DUE DILIGENCE & 11 & 0.895 & & \\
Company & 5 & 0.951 & & \\
Valuation & 3 & 0.679 & 2 & \\
Personnel & 3 & 0.883 & & \\
5. RELIGIOUSITY & 4 & 0.723 & & \\
6. READINESS & 13 & 0.858 & & \\
\hline
\end{tabular}

\section{Conclusion}

The goal of the study is to identify and assess the factors that influence covid-19 vaccination preparedness in Terengganu. To check and validate the study items, a two-stage pilot test was conducted. In the first stage, 88 responses were collected, and factor analysis was performed. Because more than $20 \%$ of the items in the first stage of the pilot test were discarded, the researchers decided to evaluate and amend the items before conducting the second stage. In the second stage, 30 responses were collected, and the item's internal 
consistency improved from the first stage. Both stages of the data were free of missing data and outliers. Because this is a pilot study with a limited sample size, it is still too early to make any definitive inferences. Future research with a bigger sample of respondents may yield more compelling conclusions.

\section{References}

Al-Mohaithef, M., \& Padhi, B. K. (2020). Determinants of COVID-19 vaccine acceptance in Saudi Arabia: a web-based national survey. Journal of multidisciplinary healthcare, 13, 1657.

Allport, G. W., \& Ross, J. M. (1967). Personal religious orientation and prejudice. Journal of personality and social psychology, 5(4), 432.

Alqudeimat, Y., Alenezi, D., AlHajri, B., Alfouzan, H., Almokhaizeem, Z., Altamimi, S., ... \& Ziyab, A. H. (2021). Acceptance of a COVID-19 vaccine and its related determinants among the general adult population in Kuwait. Medical Principles and Practice.

Babbie, E. (2004). Sociology: An idea whose time has come. Sociological Perspectives, 47(4), 331-338.

Bonnitcha, J., \& McCorquodale, R. (2017). The concept of 'due diligence'in the UN guiding principles on business and human rights. European Journal of International Law, 28(3), 899-919.

Creswell, J. W. (2010). Mapping the developing landscape of mixed methods research. SAGE handbook of mixed methods in social \& behavioral research, 2, 45-68.

El-Elimat, T., AbuAlSamen, M. M., Almomani, B. A., Al-Sawalha, N. A., \& Alali, F. Q. (2021). Acceptance and attitudes toward COVID-19 vaccines: a cross-sectional study from Jordan. Plos one, 16(4), e0250555.

Elkin, L. E., Pullon, S. R., \& Stubbe, M. H. (2020). 'Should I vaccinate my child?'comparing the displayed stances of vaccine information retrieved from Google, Facebook and YouTube. Vaccine, 38(13), 2771-2778.

Galbraith-Gyan, K. V., Lechuga, J., Jenerette, C. M., Palmer, M. H., Moore, A. D., \& Hamilton, J. B. (2019). HPV vaccine acceptance among African-American mothers and their daughters: an inquiry grounded in culture. Ethnicity \& health, 24(3), 323-340.

Geiger, M., Rees, F., Lilleholt, L., Souza S., Ana P., Zettler, I.,Wilhelm, O.,Betsch, C., \& Böhm, R. (2021). Measuring the 7Cs of vaccination readiness. European Journal of Psychological Assessment. in press.

Graziano, A. M., \& Raulin, M. L. (2004). A Second Look at Field Research: Field Experiments, Program Evaluation and Survey Research. Research Methods: A Process of Inquiry, 310311.

Hagemeister, M. H., Stock, N. K., Ludwig, T., Heuschmann, P., \& Vogel, U. (2018). Self-reported influenza vaccination rates and attitudes towards vaccination among health care workers: results of a survey in a German university hospital. Public health, 154, 102-109.

Hair Jr, J. F., Sarstedt, M., Ringle, C. M., \& Gudergan, S. P. (2017). Advanced issues in partial least squares structural equation modeling. saGe publications.

Hair, J. F., Barry, J. B., Rolph, E. A., \& Rolph, E. A. (2010). Multivariate data analysis. Pearson Prentice Hall.

Harapan, H., Wagner, A. L., Yufika, A., Winardi, W., Anwar, S., Gan, A. K., ... \& Mudatsir, M. (2020). Acceptance of a COVID-19 vaccine in southeast Asia: A cross-sectional study in Indonesia. Frontiers in public health, 8. 
Ho, R. (2006). Handbook of univariate and multivariate data analysis and interpretation with SPSS. CRC press.

Koenig, H. G., \& Büssing, A. (2010). The Duke University Religion Index (DUREL): a five-item measure for use in epidemological studies. Religions, 1(1), 78-85.

Kwok, K. O., Li, K. K., Wei, W. I., Tang, A., Wong, S. Y. S., \& Lee, S. S. (2021). Influenza vaccine uptake, COVID-19 vaccination intention and vaccine hesitancy among nurses: A survey. International journal of nursing studies, 114, 103854.

Lackner, C. L., \& Wang, C. H. (2021). Demographic, psychological, and experiential correlates of SARS-CoV-2 vaccination intentions in a sample of Canadian families. Vaccine: $X, 8$, 100091.

Lehrer, K. (2018). Theory of knowledge. Routledge.

MacDonald, N. E. (2015). Vaccine hesitancy: Definition, scope and determinants. Vaccine, 33(34), 4161-4164.

McPhetres, J., \& Zuckerman, M. (2018). Religiosity predicts negative attitudes towards science and lower levels of science literacy. PloS one, 13(11), e0207125.

Musa, R., Hashim, N., Rashid, U. K., \& Naseruddin, J. (2017). Accelerating startups: the role of government assistance programs and entrepreneurial orientation. Int. J. Econ. Res, 14, 131-147.

Nanni, Angeline, Stefanie Meredith, Stephanie Gati, Karin Holm, Tom Harmon, and Ann Ginsberg. "Strengthening global vaccine access for adolescents and adults." Vaccine 35, no. 49 (2017): 6823-6827.

Napolitano, F., Napolitano, P., \& Angelillo, I. F. (2017). Seasonal influenza vaccination in pregnant women: knowledge, attitudes, and behaviors in Italy. BMC infectious diseases, 17(1), 1-7.

Nunally, J., \& Bernstein, L. (1994). Psychometric Theory. New York: MacGrow-Hill Higher.

Nunan, D., Malhotra, N. K., \& Birks, D. F. (2020). Marketing Research: Applied Insight. Pearson UK.

Rheu, M. (2020). Attitude. The International Encyclopedia of Media Psychology, 1-12.

Riccò, M., Razio, B., Panato, C., Poletti, L., \& Signorelli, C. (2017). Knowledge, attitudes and practices of agricultural workers towards tetanus vaccine: a field report. Ann Ig, 29(4), 239-55.

Rosli, M. M., \& Sidek, S. (2013). The Impact of innovation on the performance of small and medium manufacturing enterprises:: Evidence from Malaysia. Journal of Innovation Management in Small \& Medium Enterprises, 2013, 1.

Rosso, A., Massimi, A., De Vito, C., Adamo, G., Baccolini, V., Marzuillo, C., ... \& Villari, P. (2019). Knowledge and attitudes on pediatric vaccinations and intention to vaccinate in a sample of pregnant women from the City of Rome. Vaccine, 37(14), 1954-1963.

Sekaran, U., \& Bougie, R. (2016). Research Methods For Business 7th ed. John Wiley.

Uchino, B. N., Bowen, K., de Grey, R. K., Mikel, J., \& Fisher, E. B. (2018). Social support and physical health: Models, mechanisms, and opportunities. In Principles and concepts of behavioral medicine (pp. 341-372). Springer, New York, NY.

Vergara, R. J. D., Sarmiento, P. J. D., \& Lagman, J. D. N. (2021). Building public trust: a response to COVID-19 vaccine hesitancy predicament. Journal of public health (Oxford, England).

Wang, K., Wong, E. L. Y., Ho, K. F., Cheung, A. W. L., Chan, E. Y. Y., Yeoh, E. K., \& Wong, S. Y. S. (2020). Intention of nurses to accept coronavirus disease 2019 vaccination and change of intention to accept seasonal influenza vaccination during the coronavirus disease 2019 pandemic: A cross-sectional survey. Vaccine, 38(45), 7049-7056. 
Wittink, D. R., \& Bayer, L. R. (2003). The measurement imperative. Marketing Research, 15(3), 19-19.

Wong, M. C., Wong, E. L., Huang, J., Cheung, A. W., Law, K., Chong, M. K., ... \& Chan, P. K. (2021). Acceptance of the COVID-19 vaccine based on the health belief model: A population-based survey in Hong Kong. Vaccine, 39(7), 1148-1156.

Zagzebski, L. (2017). What is knowledge?. The Blackwell guide to epistemology, 92-116. 